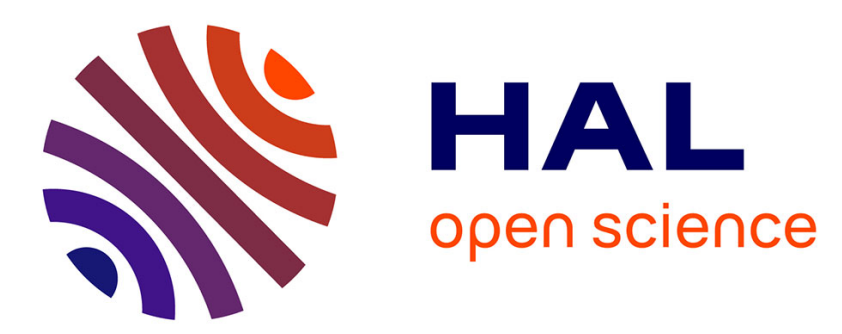

\title{
Physico-chemical deformations of solidifying cementitious systems: multiscale modelling
}

Frédéric Grondin, M. Bouasker, Pierre Mounanga, Abdelhafid Khelidj, Annick

Perronnet

\section{- To cite this version:}

Frédéric Grondin, M. Bouasker, Pierre Mounanga, Abdelhafid Khelidj, Annick Perronnet. Physicochemical deformations of solidifying cementitious systems: multiscale modelling. Materials and structures, 2010, 43 (1 2), pp.151-165. 10.1617/s11527-009-9477-z . hal-01007185

\section{HAL Id: hal-01007185 \\ https://hal.science/hal-01007185}

Submitted on 29 Nov 2017

HAL is a multi-disciplinary open access archive for the deposit and dissemination of scientific research documents, whether they are published or not. The documents may come from teaching and research institutions in France or abroad, or from public or private research centers.
L'archive ouverte pluridisciplinaire HAL, est destinée au dépôt et à la diffusion de documents scientifiques de niveau recherche, publiés ou non, émanant des établissements d'enseignement et de recherche français ou étrangers, des laboratoires publics ou privés. 


\title{
Physico-chemical deformations of solidifying cementitious systems: multiscale modelling
}

\author{
F. Grondin · M. Bouasker $\cdot$ P. Mounanga $\cdot$ \\ A. Khelidj · A. Perronnet
}

\begin{abstract}
At early stages of hydration and in autogenous conditions (no mass transfer with the outside), solidifying cementitious systems exhibit dimensional variations following two main processes: Le Chatelier contraction (also called chemical shrinkage) and self-desiccation shrinkage causing autogenous shrinkage. Chemical shrinkage results from the difference between the specific volumes of reactants (anhydrous cement and water) and hydration products. Early-age autogenous shrinkage is generally attributed to the development of a negative capillary pressure in the porous network related to the water consumption by the hydration reactions. If restrained, deformations associated to these shrinkages can induce the development of internal stresses high enough to generate cracking of the hardening material. The purpose of this study is to propose a multiscale approach to model the rate of self-desiccation shrinkage of cementitious materials at very early-age, between 0 and $48 \mathrm{~h}$. Within the first hours, Le Chatelier contraction is computed from a
\end{abstract}

F. Grondin $(\bowtie)$

Institut de Recherche en Génie Civil et Mécanique, UMR-CNRS 6183, Centrale Nantes, BP 92101,

44321 Nantes cedex 3, France

e-mail: frederic.grondin@ec-nantes.fr

M. Bouasker - P. Mounanga - A. Khelidj - A. Perronnet Institut de Recherche en Génie Civil et Mécanique, UMR-CNRS 6183, IUT Saint-Nazaire, Université de

Nantes, 44600 Saint-Nazaire, France formulation suggested in a later work which is based on the chemical equations of hydration and the specific volume of each phase. Then, when the setting of the cement paste takes place, the autogenous shrinkage is calculated according to the evolution of the capillary pressure and the stiffness of the cement paste. The stiffness is calculated by applying a classical homogenization method. Computed results are discussed and analyzed. Good agreements between experiments and simulations are achieved and a sensitivity study is performed to assess the influence of the cement fineness and the aggregate volume fraction on early-age autogenous strain.

Keywords Multiscale modelling .

Self-desiccation shrinkage $\cdot$ Cementitious materials . Early-age

\section{Introduction}

The durability of structures is based on the knowledge of the material properties used in their design. The mechanical properties of cementitious materials vary during the cement paste hydration. The hydration process depends on the initial cement composition and the water volume used. During this process, one can observe a volume variation of the cement paste and a transformation of the material from a semi-liquid phase with a visco-elastic behaviour to a solid phase. Under self-desiccation 
conditions, the setting and the hardening of cementitious matrices are accompanied by strains related to the release of the heat of hydration, to Le Chatelier contraction and to the self-desiccation of the porous network. The release of the heat of hydration can induce an increase of temperature of about $30-50^{\circ} \mathrm{C}$ in massive concrete structures $[2,7,55]$. Le Chatelier contraction is a phenomenon related to the phase change of anhydrous elements of the cement (clinker) in hydrous elements. This chemical transformation is associated to a decrease of the specific volume of the cement paste $[32,46]$. The self-desiccation is related to the progressive desaturation of the porous medium caused by the water consumption during the hydration process. The self-desiccation shrinkage prevails on the chemical shrinkage at the setting time. According to various studies, it would be associated mainly to the capillary pressure which increases with the reduction in interstitial water used for the cement hydration [31]. Strains observed at early-age are particularly intense in the case of cementitious materials with a low water-to-cement ratio (W/C) $[8,33]$ and can be at the origin of an early age cracking risk [49]. If the strains of thermal origin can be simply evaluated from the thermal history of material and the knowledge of its thermo-physical properties [4, 19, 39] and its thermo-mechanical properties [15, 29, 35, 47, 56], it is not the same for the self-desiccation shrinkage (Le Chatelier contraction and the autogenous shrinkage) whose forecast proves very complex, in particular at very early-age. This complexity can be explained by the interactions between the physicochemical phenomena (cement hydration and Le Chatelier contraction) and mechanical phenomena (the hardening and the capillary pressure) of the cementitious matrices.

Models based on empirical relations have been developed with an aim of calculating the strains due to the autogenous shrinkage in cement pastes and mortars [52]. But these macroscopic models do not take into account the microstructure heterogeneities. The homogenization methods have been developed for the determination of the equivalent mechanical properties of heterogeneous materials [1, 16]. It can be distinguished homogenization explicit methods and numerical methods. Explicit methods are based on simple representations of the microstructure with analytical resolutions of cellular problems. Numerical methods allow to consider a richer microstructure but need a numerical resolution of cellular problems [11, 24, 25, 38]. Recently, these methods have been applied to the calculation of the mechanical properties and the autogenous shrinkage of cement pastes at early-age [3, 14, 45, 54]. However, these various models do not link the chemical shrinkage observed before the setting and the self-desiccation shrinkage at early-age.

In this work, we propose a model to calculate the autogenous strains rate of cement paste and mortar at very early-age. This model makes it possible to calculate, at first, the chemical shrinkage related to Le Chatelier contraction, then the autogenous shrinkage. The evolution of the microstructural properties is expressed as a function of the cement hydration degree, calculated as the ratio between the volume of the remaining anhydrous phases and their initial volume fraction. A hydro-mechanical cellular problem is solved in a representative elementary volume (REV) and the equivalent mechanical properties are deduced by applying a homogenization method, the self-consistent scheme [27], with an iterative method [48]. Then, the autogenous shrinkage defined by the macroscopic strains is relied to the local stress solutions of the cellular problem.

The first chapter of this article is dedicated to the presentation of the scientific background and the objectives of the study. The second chapter is a brief review of the cement chemistry and the relations used for the calculation of the phase volumes during the cement hydration. In the third chapter, the resolution of the hydro-mechanical problem is given in detail. In the last chapter, calculation results are compared to experimental measurements and a sensitivity study is proposed to show the influence of certain properties of the solid components on the equivalent behaviour.

\section{Research significance}

The autogenous shrinkage is one of the phenomena clearly identified as being at the origin of microcracks in cementitious materials. If the shrinkage is restrained, microcracks develop in the surrounding zone of the aggregates and through-cracks appear in the cementitious matrix. This involves an increase in porosity and consequently a loss of the containment properties of the material and an increase in its permeability. The durability of structures depends, 
amongst other things, upon the dimensional variations of the cementitious matrix at very early-age. The self-desiccation shrinkage is a physico-chemical phenomenon coupled to mechanical capillary effects due to the pore water consumption during the cement hydration. Within the first hours of hydration (since the water-cement contact until the beginning of the setting), the capillary effects can be considered as negligible. During this phase, the self-desiccation shrinkage corresponds mainly to chemical shrinkage (also called "Le Chatelier contraction") according to a decrease of the absolute volume of material involved by the chemical reactions (Fig. 1).

The work presented in this article concerns the modelling of the autogenous shrinkage of hardening cementitious matrices containing aggregates (typically mortars or concrete mixtures). This study aims at explicitly taking into account the two phases of early-age deformations, the first phase dominated by the chemical shrinkage and the second controlled by the self-desiccation and the capillary pressure within the porous medium.

Numerical models have been developed for the modelling of the hydration of cement pastes and mortars [10, 30, 41, 57]. These models are characterized by the way in which the cement particles are hydrated. In this research, we propose a micromechanical model to calculate the mechanical properties of cementitious materials at early-age by taking into account the main cement reactions. The micromechanical approach is based on the work of Bernard et al. [14]. The cementitious material is studied on different scales:

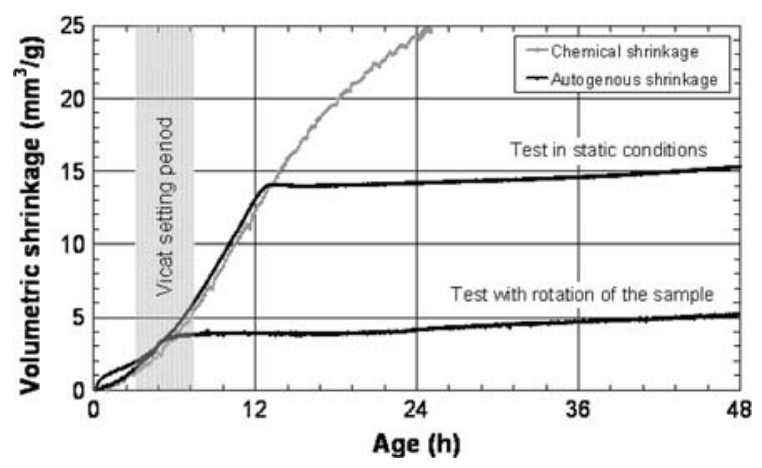

Fig. 1 Chemical and volumetric autogenous shrinkage of a CEM 1 cement paste with $W / C=0.4$ [18]
- scale I: the cement paste is considered heterogeneous and formed by a matrix represented by the calcium silicate hydrate $(\mathrm{CSH})$ containing all others components of the cement paste (clinker and formed phases during the hydration process), water pores and air voids.

- scale II: the mortar is considered heterogeneous and formed by the cement paste (homogenous on this scale) containing aggregate.

On scale I, the homogenization calculation is made with an iterative method [48]: inclusions are introduced in the matrix one by one. And at each step, a new equivalent matrix is defined by the homogenized properties obtained by averaging the intrinsic properties of the initial matrix and of the inclusion.

\section{The microstructural evolution of cement paste during the hydration process}

\subsection{Hydration kinetics of cement components}

In the objective to determine the cement paste properties at early-age, we focus at first on the formation of its microstructure. Partial volumes of the cement paste components are calculated by using the chemical relations of the cement hydration [44, 59] (see Appen$\operatorname{dix} \mathrm{A}$ ). The hydration of $\mathrm{C}_{3} \mathrm{~S}$ and $\mathrm{C}_{2} \mathrm{~S}$ gives an amorphous gel formed by $\mathrm{CSH}$ and portlandite $(\mathrm{CH})$ in the porous phase. At the first contact between cement and water, tricalcium aluminate $\mathrm{C}_{3} \mathrm{~A}$ changes to $\mathrm{C}_{3}(\mathrm{~A}, \mathrm{~F}) \mathrm{H}_{6}$. At the beginning of the setting, ettringite $\left(\mathrm{C}_{6} \mathrm{AS}_{3} \mathrm{H}_{32}\right)$ is formed in the surrounding of tricalcium aluminate $\mathrm{C}_{3} \mathrm{~A}$ with impermeable properties which slow down the hydration of $\mathrm{C}_{3} \mathrm{~A}$. When gypsum $\left(\mathrm{CS}_{\mathrm{S}} \mathrm{H}_{2}\right)$ is totally consumed, ettringite changes in monosulfate $\left(\mathrm{C}_{4} \mathrm{~A} \overline{\mathrm{S}} \mathrm{H}_{12}\right)$ with also impermeable properties. In the same way, tricalcium aluminoferrite $\mathrm{C}_{4} \mathrm{AF}$ forms ettringite, monosulfate, ferrite $\left(\mathrm{FH}_{3}\right)$ and portlandite.

The degree of hydration $\left(\xi_{X}\right)$ of each clinker is defined by its normalized affinity $\tilde{A}\left(\xi_{X}\right)$ and its characteristic time associated with the reaction $\left(\tau_{X}\right)$ in the following way [50]:

$\tau_{X} \frac{d \xi_{X}}{d t}=\tilde{A}\left(\xi_{X}\right)$

where $\tau_{X}$ is a function of the temperature $T$ and is described by the Arrhenius law: 
$\tau_{X}(T)=\tau_{X}\left(T_{0}\right) \exp \left[\frac{E_{a X}}{R}\left(\frac{1}{T_{0}}-\frac{1}{T}\right)\right]$

where $\tau_{X}\left(T_{0}\right)$ is the characteristic time at a constant temperature $T_{0}=293 \mathrm{~K}, E_{a X}(\mathrm{~J} / \mathrm{mol})$ the activation apparent energy of each clinker phase $X$ and $R$ the perfect gas constant $(R=8.314 \mathrm{~J} / \mathrm{mol} / \mathrm{K})$. To take into account the influence of the cement fineness $(\phi)$, the kinetics parameters, obtained for a cement of a fineness $\phi=3602 \mathrm{~cm}^{2} / \mathrm{g}$ and an average particle size $r=5.10^{-4} \mathrm{~cm}$ [14], can be corrected by an adjustment of $\tau_{X}\left(T_{0}\right)$ as follow:

$\tau_{X}\left(T_{0}, \phi\right)=\frac{\phi_{0}}{\phi} \tau_{X}\left(T_{0}, \phi_{0}\right)$

The hydration reaction is developed in three steps: dissolution of the clinker phases during the induction period, nucleation according to the Avrami model [5, $6]$ and diffusion according to the work of Fuji and Kondo [22]. The calculation of $\tilde{A}\left(\xi_{X}\right)$ at each step is given in detail in [14].

This approach considers an individual kinetic rate for each cement clinker and does not take into account interactions between particles. In fact, within the first hours, the hydration of $\mathrm{C}_{3} \mathrm{~S}$ is slow down by the hydration of $\mathrm{C}_{3} \mathrm{~A}$ because it forms aluminates which surround particles of $\mathrm{C}_{3} \mathrm{~S}$ and limit their contact with water. Otherwise, the hydration of $\mathrm{C}_{3} \mathrm{~S}$ is fast and the cementitious material is quickly very rigid. That is giving a quasi-brittle material. So, in adding $\mathrm{C}_{3} \mathrm{~S}$ in cement, its hydration leads to a better handiness of the material and reduces the brittleness. In this work, the main objective is to propose a model for the calculation of the elastic behaviour of cementitious materials. And the hydration model is a tool used to calculate the evolution of the volume fraction of each phases. So, any performed hydration models can be used in coupling with the elastic model presented below.

\subsection{Calculation of the volume of the cement phases}

The volume of each residual cement phase $\left(V_{X}\right)$ can be calculated as [14]:

$V_{X}(t)=V_{C 0} f_{X}\left(1-\xi_{X}(t)\right)$

where $V_{C O}$ is the initial volume of cement and $f_{X}$ the initial mass fraction of cement phase $X$. In the same way, the volume of the residual water is equal to:

$V_{E}(t)=V_{E 0}-\sum V_{E}^{X} \xi_{X}(t)$

with

$V_{E}^{X}=V_{C 0} \frac{n_{E} \rho_{C} f_{X} / M_{X}}{n_{X} \rho_{E} / M_{E}}$

where $V_{E 0}$ is the initial volume of water, $V_{E}^{X}$ the volume of water consumed to hydrate the cement phase $X$ of molar mass $M_{X}, M_{E}$ the molar mass of water and $\frac{n_{E}}{n_{X}}$ the mole number of water $\left(n_{E}\right)$ consumed to hydrate one mole of cement phase $\left(n_{X}\right)$ of the apparent density $\rho_{C} f_{X}$. Gypsum is consumed with $\mathrm{C}_{3} \mathrm{~A}$ and $\mathrm{C}_{4} \mathrm{AF}$ and it is supposed that the consumption kinetic rate of gypsum can be defined by the hydration rate of these two clinkers. So we calculate the volume of gypsum as follow:

$V_{\text {gyp }}(t)=V_{C 0} f_{\text {gyp }}\left(1-\beta \cdot\left(3 \xi_{\mathrm{C}_{3} \mathrm{~A}}(t)-3 \xi_{\mathrm{C}_{4} \mathrm{AF}}(t)\right)\right)$

where the factor 3 is the stoichiometric coefficient of the chemical reactions (see Appendix A) and $\beta$ a constant parameter which depends on the water-tocement ratio. In this study $\beta$ is chosen equal to 2 , respectively 3 , for $W / C=0.4$, respectively $W /$ $C=0.3$. This coefficient does not affect the hydration rate but allows to have an uniform consumption of gypsum. Then, when gypsum is totally consumed, ettringite changes in monosulfate and it is supposed the following relation for the volume of ettringite versus time:

$V_{\text {ett }}(t)=V_{\text {ett }}\left(t_{g}\right)\left(1-0.5 \xi_{\mathrm{C}_{3} \mathrm{~A}}(t)-0.5 \xi_{\mathrm{C}_{4} \mathrm{AF}}(t)\right)$

where $V_{\text {ett }}\left(t_{g}\right)$ is the volume of ettringite at the beginning of the formation of monosulfate and the factor 0.5 is the stoichiometric coefficient of the chemical reactions (see Appendix A). The volume of hydrated phases can be calculated according to the volume of elements which have reacted as for the following chemical reaction:

$n_{1}^{R} V_{1}^{R}+\cdots+n_{n}^{R} V_{n}^{R} \rightarrow n_{1}^{P} V_{1}^{P}+\cdots n_{m}^{P} V_{m}^{P}$

we can write:

$V_{i}^{P}(t)=\sum_{j=1}^{n} C_{i}^{j} \xi_{j}(t)$

with 
$C_{i}^{j}=V_{C 0} \frac{n_{i}^{P} \rho_{C} f_{j} / M_{j}}{n_{j}^{R} \rho_{i} / M_{i}} \quad i=1, m$

where $i$ respectively $j$, is the exponent relied to products, respectively to reactants. The volume of each component in the microstructure of the cement paste is calculated along the hydration. These volumes are then used in a multiscale approach to compute the mechanical properties of cementitious materials.

\section{The multiscale approach}

\subsection{The equivalent hydro-mechanical behaviour law}

We consider a representative volume $V$ formed by a matrix $V_{m}$ and several types of inclusions, supposed to be spherical and with the same size. Inclusions are defined by their volume fraction in $V: \sum_{i} V_{i}=V_{s}$, where $V_{s}$ is the whole volume of the solid phases in $V$. We call $\Gamma_{m i}$ the interface between the matrix and the inclusion $i$ and $\partial V$ the exterior boundary of the volume $V$. The choice of the matrix depends on the evolution of the cement hydration. The material is very "fluid" before the setting of the cement paste and its elastic modulus can be neglected [19]. At the beginning of setting, the material turns into a "solid" and its elastic modulus increases according to the age of the cement paste. The stiffness of the material starts to increase when there is percolation of the solid elements in the volume. Some numerical methods [10, 54] and experimental methods [58] have been developed for the determination of the percolation threshold. In the model presented in this paper, we suppose a theoretical percolation defined by the self-consistent scheme for which it takes place when the volume fraction of the solid phase $\left(V_{s}\right)$ becomes higher than that of the liquid phase $\left(V_{l}\right)$. So, before the setting of the cement paste, the matrix is formed by the capillary porosity (water and voids) and the solid phases are the inclusions. After the setting, we consider a matrix formed by the CSH phase in which all other phases are included as well as the capillary porosity.

Based on the methods proposed for the calculation of the swelling of clay [34], we define the cement paste as a biphasic medium composed of:
- a porous medium $\left(V_{I}\right)$ formed by the anhydrous and hydrous elements,

- a medium $\left(V_{I I}\right)$ formed by the capillary porosity with the capillary pressure $p_{c}$.

These two phases are supposed to have an isotropic behaviour law. To calculate the homogenized elastic behaviour, a uniform strain field tensor $\underline{E}$ is applied on the volume boundaries. This implies local displacements fields $\underline{u}(\underline{y})$, local strain fields $\underline{\underline{\varepsilon}}(\underline{y})$ and local stress fields $\underline{\underline{\sigma}}(\bar{y})$ in each point $\underline{y}$ of $V$ which are solutions of the following cellular problem:

$\underline{\underline{\sigma}}(\underline{y})={\underset{\sim}{0}}^{0}(\underline{y}): \underline{\underline{\varepsilon}}(\underline{y}) \quad$ in $V_{I}$

$\underline{\underline{\sigma}}(\underline{y})=-p_{c} \underline{\underline{\delta}}$ in $V_{I I}$

where $C^{0}$ represents the stiffness tensor of $V_{I}$ under drained conditions. By applying the Levin's theorem for the homogenization of elastic heterogeneous media, the resolution of the cellular problem allows to deduce the homogenized behaviour law on the upper scale [20]. The homogenized behaviour law is defined by the relation between the average stresses $\langle\underline{\underline{\sigma}}\rangle_{V}$ and the average strains $\langle\underline{\underline{\varepsilon}}\rangle_{V}$ where $\underline{\underline{\sigma}}$ is the stress tensor solution of the cellular problem:

$$
\begin{aligned}
\underline{\underline{\Sigma}} & =\langle\underline{\underline{\sigma}}\rangle_{V}=\frac{1}{|V|} \int_{V} \underline{\underline{\sigma}}(\underline{y}) d y={\underset{\sim}{C}}^{h o m}:\langle\underline{\underline{\varepsilon}}\rangle_{V}+\underline{\underline{\Sigma}}^{p} \\
& ={\underset{\sim}{C}}^{h o m}: \underline{\underline{E}}+\underline{\underline{\Sigma}}^{p}
\end{aligned}
$$

where $C^{\text {hom }}$ is the homogenized stiffness tensor of the material and $\underline{\Sigma}^{p}$ is the prestress field on the upper scale defined by:

$$
\begin{aligned}
& \left.{\underset{\sim}{C}}^{h o m}=f_{1} \underset{\sim}{C^{1}}: \underset{\sim}{\langle A}\right\rangle_{I}+f_{2} C_{\sim}^{2}:\langle\underset{\sim}{A}\rangle_{I I} \\
& \underline{\underline{\Sigma}}^{p}=\left\langle\underline{\underline{\underline{\sigma}}}^{p}: \underset{\sim}{A}\right\rangle_{V}=\left\langle{ }^{t} A: \underline{\underline{\sigma}}^{p}\right\rangle_{V} \\
& =f_{1}\left\langle{ }_{\sim}^{t} A\right\rangle_{I}: \underline{\underline{\sigma}}_{I}^{p}+f_{2}\left\langle{ }_{\sim}^{t} A\right\rangle_{I I}: \underline{\underline{\sigma}}_{I I}^{p}=\left(-p_{c}\right) f_{2}\left\langle{ }_{\sim}^{t} A\right\rangle_{I I}: \underline{\underline{\delta}}
\end{aligned}
$$

where $C^{1}$ represents the homogenized stiffness tensor of the medium $V_{I}$ and $f_{1}$ and $f_{2}$ indicate, respectively, the volume fraction of medium I and medium II and $C^{2}$ the stiffness tensor of the capillary porosity of the medium II defined by the water compressibility in the unsaturated pores. $A$ is the strain concentration tensor as its average its equal to identity and it can be decomposed in each domains of the material as $\langle A\rangle_{I}$ and $\langle\underset{\sim}{\langle A}\rangle_{I I}$ are the strain concentration tensors in $\widetilde{V}_{I}$, 
respectively in $V_{I I}$. The strain concentration tensors are determined by resolving the Eshelby's problem [21] (cf. Appendix B). By considering an isotropic elastic behaviour for the homogenized medium, the homogenized stiffness tensor can be defined by the homogenized compressibility and shear moduli, respectively $k^{\text {hom }}$ and $\mu^{\text {hom }}$ :

C $^{\text {hom }}=3 k^{\text {hom }} I_{\sim}^{\text {vol }}+2 \mu^{\text {hom }} I_{\sim}^{\text {dev }}$

$k^{\text {hom }}$ and $\mu^{\text {hom }}$ check the equation system obtained by using the expressions of (27), (28) and (29) for an isotropic medium:

$\sum_{i=1}^{2} f_{i} \frac{k_{i}-k^{\text {hom }}}{1+\alpha\left(k_{i}-k^{\text {hom }}\right) / k^{\text {hom }}}=0$

$\sum_{i=1}^{2} f_{i} \frac{\mu_{i}-\mu^{\text {hom }}}{1+\beta\left(\mu_{i}-\mu^{\text {hom }}\right) / \mu^{\text {hom }}}=0$

with

$\alpha=\frac{3 k^{\text {hom }}}{3 k^{\text {hom }}+4 \mu^{\text {hom }}} \quad$ and $\quad \beta=\frac{6\left(k^{\text {hom }}+2 \mu^{\text {hom }}\right)}{5\left(3 k^{\text {hom }}+4 \mu^{\text {hom }}\right)}$

where $f_{i}, k_{i}$ and $\mu_{i}$ are the volume fractions, the compressibility and the shear moduli of each phases $i$, respectively. The prestress field is then written as follow:

$$
\begin{aligned}
\underline{\underline{\Sigma}}^{p}= & {\left[-f_{2} p_{c} \underline{\underline{\delta}}\right] } \\
& +\left[k^{h o m}-f_{2} k_{2}-\left(1-f_{2}\right) k_{1}\right] \frac{-p_{c}}{k_{2}-k_{1}} \underline{\underline{\delta}}
\end{aligned}
$$

$\underline{\underline{\Sigma}}^{p}$ can be also written in the form $-p b \underline{\underline{\delta}}[42,43]$, where $b$ is the isotropic Biot's coefficient associated to the capillary pressure $p_{c}$ :

$b=f_{2}+\frac{\left[k^{h o m}-f_{2} k_{2}-\left(1-f_{2}\right) k_{1}\right]}{k_{2}-k_{1}}$

\subsection{The capillary pressure in pores}

At the first contact between water and cement, all components are disjoined. The setting of the cement paste begins when the percolation of the solid phase, formed by the hydrous and the anhydrous phases, takes place. At this time, we can consider the formation of a capillary porosity network. Also, the
CSH gel contains a porosity network formed by smallest pores (of Angstrom order). And, during the hydration process, water leaves the capillary porosity to hydrate the residual anhydrous elements of cement by filling the $\mathrm{CSH}$ gel porosity. The desaturation of the capillary pores generates a capillary pressure $p_{c}$ which is the difference between the air pressure $\left(p_{a}\right)$ and the water pressure $\left(p_{l}\right)$ :

$p_{c}=p_{a}-p_{l}$

According to the work of Kelvin, the capillary pressure is associated to the saturating air vapor pressure, and thus the relative humidity. In a first approach, we have chosen to use an empirical law of the capillary pressure in relation to the liquid saturation $(S)$ without taking account the variation of the pore size as recommended by Powers and Brownyard [46]. This capillary pressure is deduced from isotherms measurements of air vapor desorption in cement paste and concrete [9]:

$p_{c}(S)=M\left(S^{m}-1\right)^{(1-1 / m)}$

where $M$ and $m$ are constant parameters depending on the material, such as for a cement rich in $\mathrm{C}_{3} \mathrm{~S}$ (57.28\%):

- $M=37.5479 \mathrm{MPa}, m=2.1648$ for a cement paste with a water-to-cement ratio $W / C=0.34$,

- $M=18.6237 \mathrm{MPa}, m=2.2748$ for an ordinary concrete with a water-to-cement ratio $W / C=$ 0.48, an aggregate to cement ratio $A / C=5.48$ and a sand to gravel ratio $S / G=0.62$ in mass proportions.

As this pressure relation has been deduced from isotherms measurements, we do not consider the temperature effects on the capillary pressure in this study. The calculation of the liquid saturation $S$ is based on the ratio between the water volume and the total porosity volume during the hydration process. But, in the calculation of the mechanical properties, according to the relations (16), we suppose two distinct volumes: a volume fraction of pores saturated with water and a volume fraction of pores saturated with air. We have made this hypothesis because it is not possible to calculate the homogenized mechanical properties by considering unsaturated pores. 
4.3 Calculation of the cement paste shrinkage at early-age

Before the setting, the chemical shrinkage of the cement paste is the main component of the autogenous strain. The model developed by Mounanga et al. [40] is adopted to calculate the chemical shrinkage of the cement paste as:

$$
\begin{aligned}
\Delta \varepsilon(t)= & \Delta \varepsilon_{G y} M_{G y}+\Delta \varepsilon_{\mathrm{C}_{3} \mathrm{~S}} M_{\mathrm{C}_{3} \mathrm{~S}}(t) \\
& +\Delta \varepsilon_{\mathrm{C}_{2} \mathrm{~S}} M_{\mathrm{C}_{2} \mathrm{~S}}(t) \Delta \varepsilon_{\mathrm{C}_{3} \mathrm{~A}} M_{\mathrm{C}_{3} \mathrm{~A}}(t) \\
& +\Delta \varepsilon_{\mathrm{C}_{4} \mathrm{AF}} M_{\mathrm{C}_{4} \mathrm{AF}}(t)+\Delta \varepsilon_{E t t} M_{E t t}(t)
\end{aligned}
$$

where $\Delta \varepsilon_{i}$ is the chemical shrinkage (in $\mathrm{mm}^{3}$ per gram of cement) produced for the hydration of $1 \mathrm{~g}$ of the anhydrous phase $i$ and $M_{i}$ the mass fraction (in gram per gram of cement) of this phase hydrated at the time $t$. $M_{i}$ can be determined by the calculation of the phase volume. At setting, the material begins to gain stiffness and the capillary pressure starts to exert a tensile load on the mineral skeleton of the cement paste. By using the homogenized behaviour law (12) and by supposing that the volume is free to deform under a uniform pressure, we deduce the following relation for the strain field on the upper scale, corresponding to the autogenous shrinkage of the cement paste:

$$
\begin{aligned}
d E^{c p}= & \frac{1}{3 k^{h o m}}\left[-p_{c}+f_{2} p_{c}-\left(k_{c p}^{h o m}-f_{2} k_{2} .\right.\right. \\
& \left.\left.-\left(1-f_{2}\right) k_{1}\right) \frac{\sigma_{2}^{p}}{k_{2}-k_{1}}\right]
\end{aligned}
$$

where $k_{c p}^{\text {hom }}$, respectively $k^{\text {hom }}$, is the homogenized compressibility modulus of the cement paste, respectively of the solid phase.

\subsection{Calculation of the mortar shrinkage at early-age}

Mortar and concrete contain sand grains and aggregate mixed in the cement paste in a random way. In the model presented in this paper, the aggregate size distribution supposes a single size and a spherical shape for all aggregate. We apply the Mori-Tanaka homogenization method on the mortar scale to calculate the compressibility modulus $\left(k_{m}^{h o m}\right)$ and the autogenous shrinkage at earlyage $\left(d E^{m}\right)$ [45]: $d E^{m}=f_{c p} \frac{k_{c p}^{h o m}}{k_{m}^{h o m}}\left[\sum_{r} \frac{f_{r}}{1+{\underset{\sim}{P}}^{1} \frac{k_{r}-k_{c p}^{h o m}}{k_{m}^{h o m}}}\right]^{-1} d E^{c p}$

where $f_{r}$ is the volume fraction of aggregate and $k_{r}$ their compressibility modulus. In this equation, the $\sum$ relation allows to add aggregate with different mechanical properties.

In cementitious materials containing aggregate, we can observe, during the hydration process, the formation of an interfacial transition zone (ITZ) around aggregate. Most of the studies carried out on ITZ generally concluded on higher porosity and lower mechanical properties [36, 37]. Within the framework of this study, scanning electron microscope (SEM) observations (Fig. 2) have shown that ITZ is significant only after $48 \mathrm{~h}$ in mortars with various $A / C$ and $W / C$ [17]. So, we can consider that the mechanical and diffusion properties of the ITZ are close to that of the bulk paste before $48 \mathrm{~h}$. At $48 \mathrm{~h}$ many micro-cracks were observed in the cement paste in the vicinity of the aggregates. These microcracks can nucleate, on the one hand, during the sample preparation and particularly by the drying during the SEM observation and, on the other hand, by the restrained shrinkage and the internal stress relaxation of the cement paste. Additional tests will be made in order to quantify the relative share of each one of these phenomena. In this study, we focus on the behaviour of cementitious materials between 0 and $48 \mathrm{~h}$ and the nucleation of micro-cracks are not modeled.

\section{Application of the model, comparison with experimental results and sensitivity study}

\subsection{Input parameters}

The model presented here is based on the knowledge of the material component properties. Calculations have been made for a cement of type CEM I 52.5 (Saint Pierre la Cour). The Bogue's composition has been kept constant: $62 \% \mathrm{C}_{3} \mathrm{~S}, 11 \% \mathrm{C}_{2} \mathrm{~S}, 8 \% \mathrm{C}_{3} \mathrm{~A}, 8 \%$ $\mathrm{C}_{4} \mathrm{AF}$ and $7 \% \mathrm{C} \overline{\mathrm{S}} \mathrm{H}_{2}$ with a fineness $\phi=3390 \mathrm{~cm}^{2} / \mathrm{g}$. The kinetic parameters of the cement hydration and the elastic moduli of the cement paste phases have 
Fig. 2 SEM micrographs showing the time evolution of the ITZ microstructure of a mortar specimen (CEM I cement, $\mathrm{W} / \mathrm{C}=0.3$, Le Boulonnais sand, $\mathrm{S} / \mathrm{C}=1$ ). $\mathrm{S}$ : sand, $\mathrm{CP}$ : cement paste $(1000 \times)$. a At $5 \mathrm{~h}$ of hydration. b At $10 \mathrm{~h}$ of hydration. c At $48 \mathrm{~h}$ of hydration. d At $96 \mathrm{~h}$ of hydration

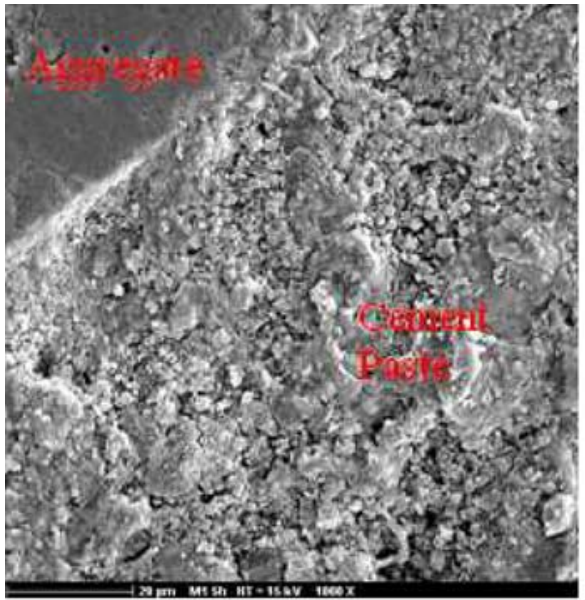

(a)

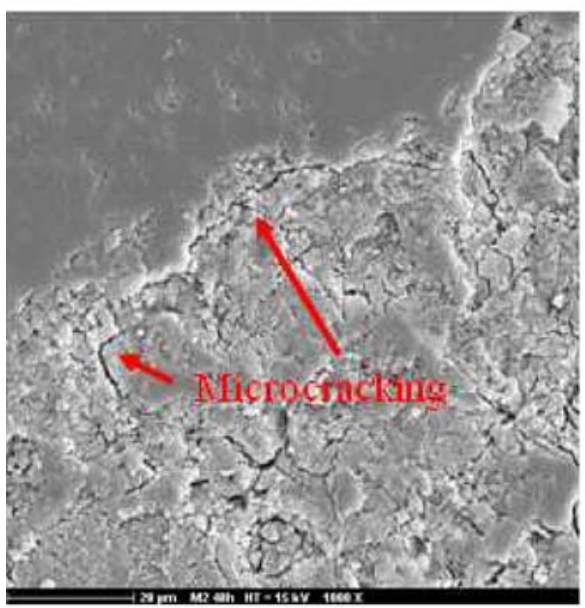

(c)

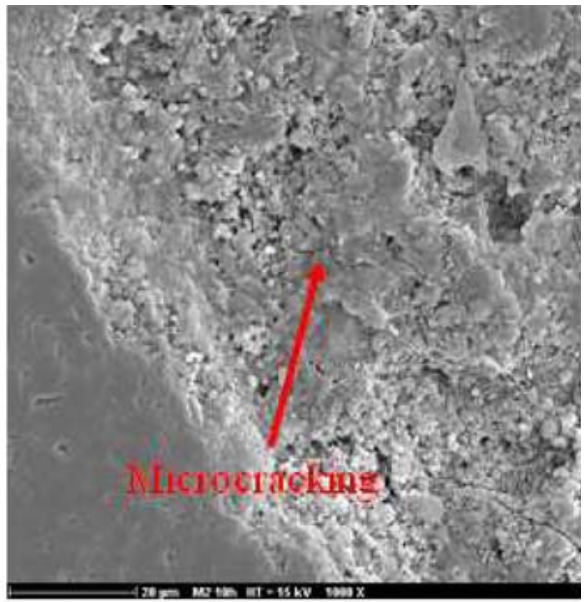

(b)

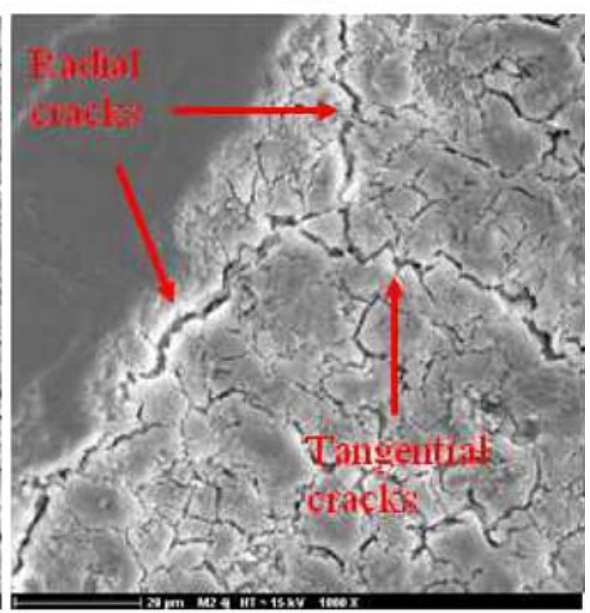

(d) been chosen from the literature review $[14,26]$ and the elastic properties are presented in Table 1. The calculation of the homogenized elastic properties, by applying the self-consistent scheme, needs the knowledge of the elastic properties of all phases. So, we consider all phases as elastic inclusions and we characterize air filed pores and water filed pores by a compressibility modulus and a shear modulus. It can be noted for some Young's moduli that their values are between a minimum $\left(E_{\text {min }}\right)$ and a maximum $\left(E_{\text {max }}\right)$. In Table $1, \mathrm{CSH}_{a}$ and $\mathrm{CSH}_{b}$ represent, respectively, the $\mathrm{CSH}$ with a low-density and the $\mathrm{CSH}$ with a high-density. The $\mathrm{CSH}_{a}$ is formed around $\mathrm{C}_{3} \mathrm{~S}$ and $\mathrm{C}_{2} \mathrm{~S}$ during at very early age and the $\mathrm{CSH}_{b}$ is formed around the $\mathrm{CSH}_{a}$ in a second step [28, 53].

As written above, the hydration process occurs in three steps: the dissolution, the nucleation and the diffusion. The parameters of the nucleation have been chosen in the literature review [13]. The diffusion depends on the permeability of the $\mathrm{CSH}$ gel pores surrounding the clinker. Calculations for a cement paste with a water-to-cement ratio $W / C=0.4$ have been performed to rely the start of the diffusion to the liquid saturation which is equal to $99.2 \%$. In fact, the saturation threshold depends on the initial $W / C$ and the type and fineness of the cement used. One of the perspectives of this work is to identify correctly this saturation threshold by measuring the increase of the capillary pressure.

\subsection{Experimental tests}

Hydration degree, chemical and autogenous shrinkage and Young's modulus measurements have been achieved for cement paste prepared with cement whose composition is described in the previous 
Table 1 Elastic moduli of the cement paste phases

\begin{tabular}{lll}
\hline Phase & E (GPa) & $v[-]$ \\
\hline $\mathrm{CSH}_{a}$ & $19-23.9$ & 0.25 \\
$\mathrm{CSH}_{b}$ & $27-35$ & 0.25 \\
$\mathrm{CH}$ & $33-48$ & 0.324 \\
$\mathrm{C}_{3} \mathrm{~S}$ & $128-152$ & 0.314 \\
$\mathrm{C}_{2} \mathrm{~S}$ & $110-150$ & 0.314 \\
$\mathrm{C}_{3} \mathrm{~A}$ & $110-170$ & 0.314 \\
$\mathrm{C}_{4} \mathrm{AF}$ & $100-170$ & 0.314 \\
$\mathrm{C}_{6} \mathrm{~A} \overline{\mathrm{S}}_{3} \mathrm{H}_{32}$ & 22.4 & 0.25 \\
$\mathrm{CS}_{2} \mathrm{H}_{2}$ & 45.7 & 0.33 \\
$\mathrm{C}_{4} \mathrm{AS} \mathrm{S}_{12}$ & 42.3 & 0.324 \\
$\mathrm{C}_{3}(\mathrm{~A}, \mathrm{~F}) \mathrm{H}_{6}$ & 22.4 & 0.25 \\
$\mathrm{FH}_{3}$ & 22.4 & 0.25 \\
\hline & $\mathrm{k}(\mathrm{GPa})$ & $\mu(\mathrm{GPa})$ \\
\hline Water & 2.2 & 0 \\
Air & 0.141 & 0 \\
\hline
\end{tabular}

section and considering two $W / C$ ratios equal to 0.3 and 0.4. All tests have been carried out at constant temperature $T=20 \pm 0.5^{\circ} \mathrm{C}$. The chemical shrinkage was measured by keeping permanent water saturation in the cement paste sample according to the protocol test described by Mounanga et al. [40].

For the measurement of the autogenous shrinkage (external shrinkage), the volume method by hydrostatic weighing was used. An original experimental device equipped with a rotating system has been developed in order to avoid bleeding and segregation effects on the measurement result [17]. Paraffin oil was used as the immersion liquid to limit the liquid absorption by the sample. The Young's modulus was deduced from measurements of wave propagation in cement paste prismatic specimens, using a nondestructive method $\left(\right.$ Grindosonic $\left.^{\odot}\right)$.

\subsection{Comparison between numerical and measurement results}

Figure 3 shows results obtained for the hydration degree of cement pastes with different $W / C$ ratios. Calculated results obtained for cement pastes with $W / C=$ 0.3 and $W / C=0.4$ are compared to experimental measurements. We can observe that the hydration degree calculated for $W / C=0.4$ is in good agreement with the experimental values. For lowest $W / C(=0.3)$,

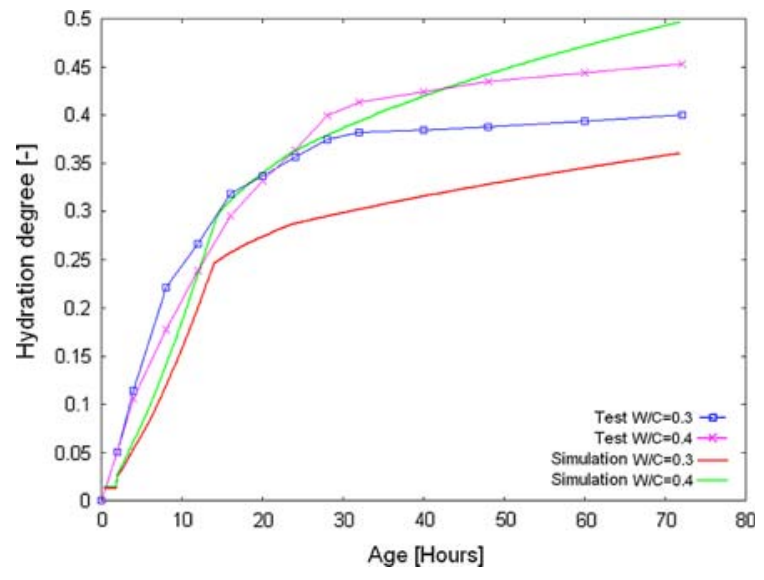

Fig. 3 Evolution of the calculated hydration degree of two cement pastes $(W / C=0.3$ and $W / C=0.4)$ and comparison with experimental measurements

the model under-estimates the hydration degree. This is due to an hypothesis made at the first hours of the hydration during the dormant period which depends on the $W / C$ ratio and on the cement type. In first approximation we have considered a constant dormant period between 0.5 and $2 \mathrm{~h}$.

By considering that the hydration degree is sufficiently representative, the model has been computed to calculate the volume phases in the cementitious material during the hydration process. The consumed and the formed phases can be distinguished, respectively, on Figs. 4 and 5.

Then, by applying the self-consistent scheme (16-17) with the knowledge of the individual mechanical properties of the material phases (Table 1) and their volume fraction calculated below,

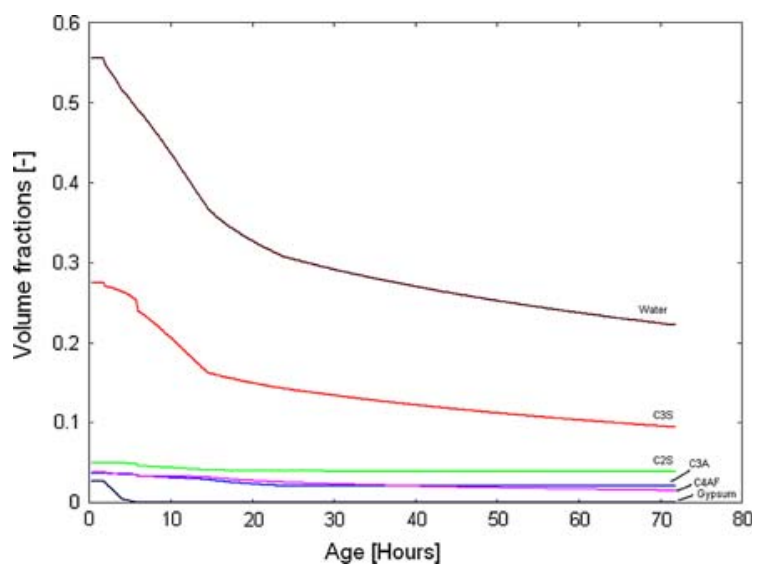

Fig. 4 Calculated volume fractions of consumed phases versus time in a cement paste with $W / C=0.4$ 


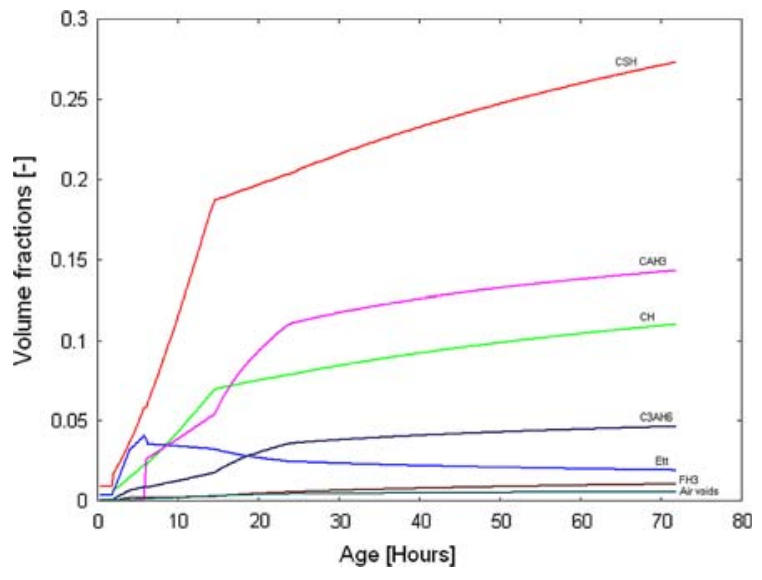

Fig. 5 Calculated volume fractions of formed phases versus time in a cement paste with $W / C=0.4$

the homogeneous Young's modulus can be computed. A calibration of the Young's moduli of the cement paste phases has been made in order to choose the best values for the homogenization calculation. The curve $E_{\text {min }}$, respectively $E_{\max }$, presented on Fig. 6 has been obtained by taking the lowest values, respectively highest values, of the Young's moduli of the cement paste phases given in Table 1.

It is observed that for the lowest values, the multiscale model can predict the Young's modulus before the diffusion phenomena and for the highest values, the model can predict the measured value at few days (3 days). So, we suggest to use the following algorithm based on a progressive increase in the moduli of phases starting from the beginning of the diffusion $\left(t=t_{d i f}\right)$ up to $t_{s}=48 \mathrm{~h}$ for which the macroscopic modulus is closed to the average value $E_{\text {avg }}=\left(E_{\min }+E_{\max }\right) / 2$ :

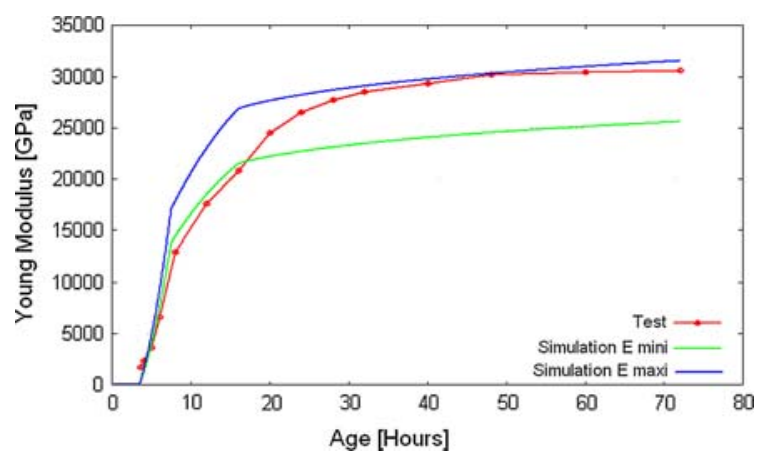

Fig. 6 Influence of the choice of the input elastic parameters on the Young's modulus
- if $t<t_{\text {dif }}, E^{i}=E_{\text {min }}^{i}$

$-\quad$ if $_{E_{\text {min }}^{i}} t_{\text {dif }}<t<t_{s}, \quad E^{i}=\left(E_{\text {avg }}^{i}-E_{\text {min }}^{i}\right) /\left(t-t_{\text {dif }}\right)+$

- if $t>t_{s}, E^{i}=E_{\text {avg }}^{i}$

Calculated results obtained for cement pastes with $W / C=0.3$ and $W / C=0.4$ are in good agreement with experimental measurements (Fig. 7).

Calculated results obtained for the chemical shrinkage and the autogenous shrinkage are compared to experimental measurements in Fig. 8. The Biot's coefficient of cement pastes has been calculated using the relation (20) and results are presented in Fig. 9. As expected, the Biot's coefficient decreases according to the decrease of the liquid saturation in pores during the hydration.

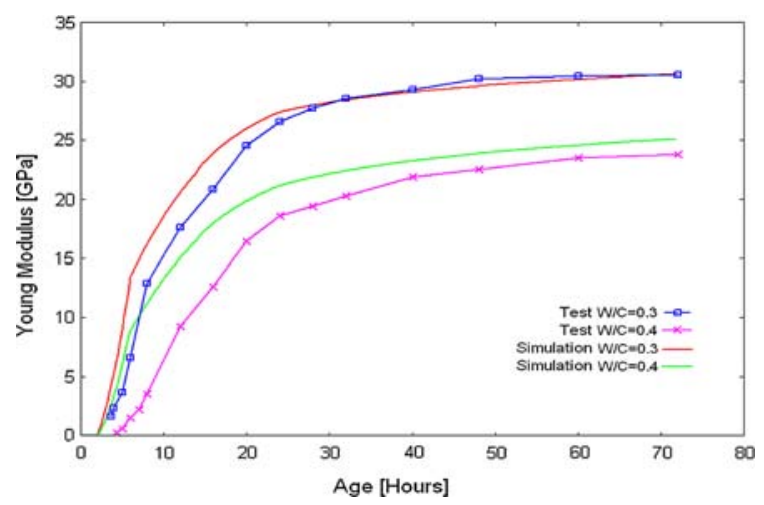

Fig. 7 Confrontation of the calculated Young's modulus and experimental measurements for two cement pastes $(W / C=0.3$ and $W / C=0.4$ )

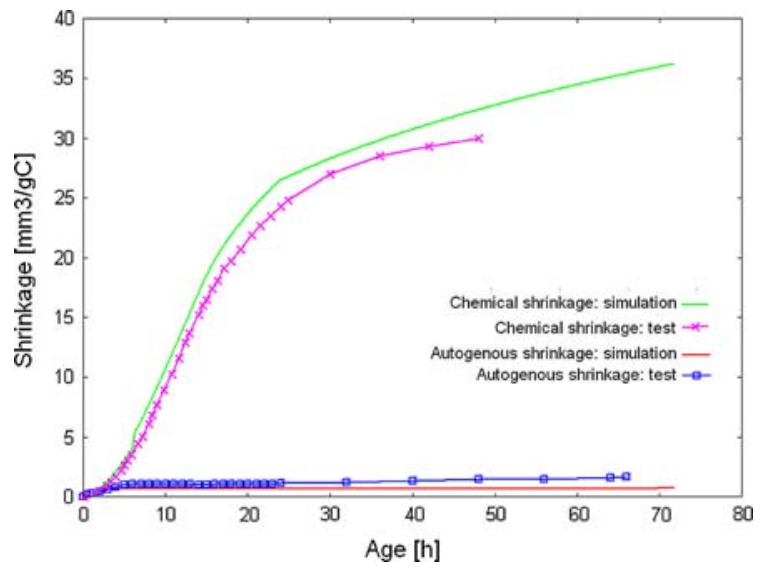

Fig. 8 The chemical shrinkage and the autogenous shrinkage of a cement paste with $W / C=0.4$ 


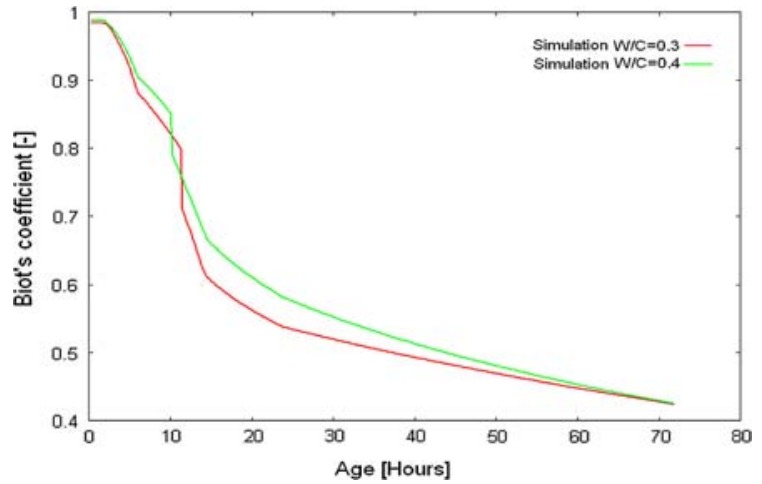

Fig. 9 Evolution of the Biot's coefficient for the two cement pastes

\subsection{Influence of the cement fineness}

The cement fineness is defined by the cement particle size distribution. Previous experimental studies have shown that an increase in the cement fineness causes an acceleration of the cement hydration and of the cement paste autogenous strain [12, 23, 51]. In the model presented in this paper, the cement fineness is an input parameter for the simulation of hydration. Calculations have been performed to quantify the influence of this parameter on the results provided by the model. The input cement properties are the same as those defined below and the $W / C$ ratio is 0.4 . Calculated results on the Young's modulus are plotted in Fig. 10 and the autogenous shrinkage in Fig. 11 for various cement fineness (the autogenous shrinkage is presented by cutting off the chemical

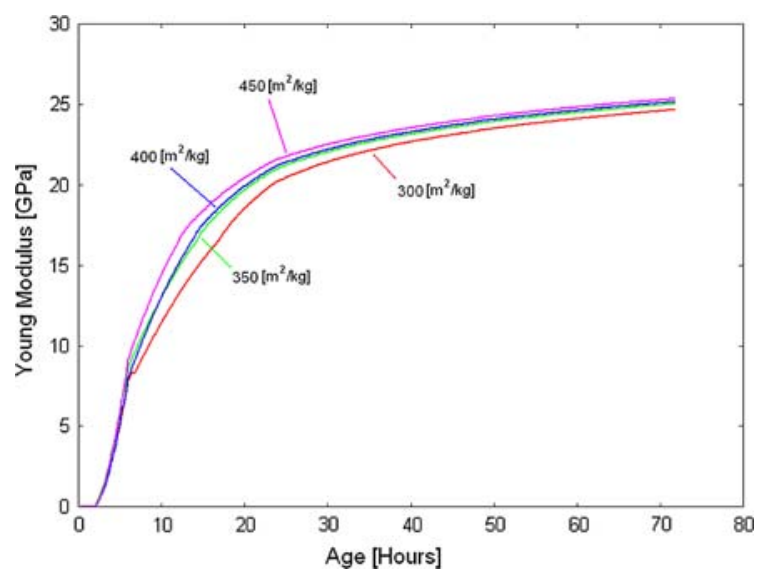

Fig. 10 Influence of the cement fineness on the Young's modulus of a cement paste with $W / C=0.4$ shrinkage phase). As expected, the highest cement fineness gives the highest stiffness and the highest volume reduction.

\subsection{Influence of the granular inclusion fraction}

In this part, we present simulation results for the early-age self-desiccation strain of mortars. The $W / C$ ratio is 0.4 and the cement fineness is $\phi_{0}=360.2 \mathrm{~m}^{2} / \mathrm{kg}$. The Young's modulus of the sand grains has been chosen equal to $60 \mathrm{GPa}$ and the Poisson's ratio equal to 0.28 . The numerical results show that the increase of the $S / C$ ratio leads to an increase of the Young's modulus (Fig. 12) and a decrease of the autogenous strain of mortars (Fig. 13). In Fig. 14 the ratio between the autogenous

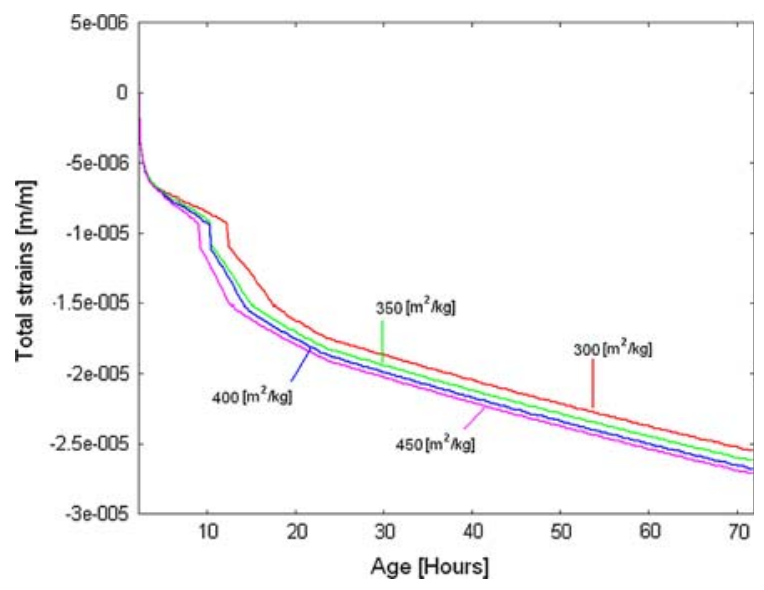

Fig. 11 Influence of the cement fineness on the autogenous shrinkage of a cement paste with $W / C=0.4$

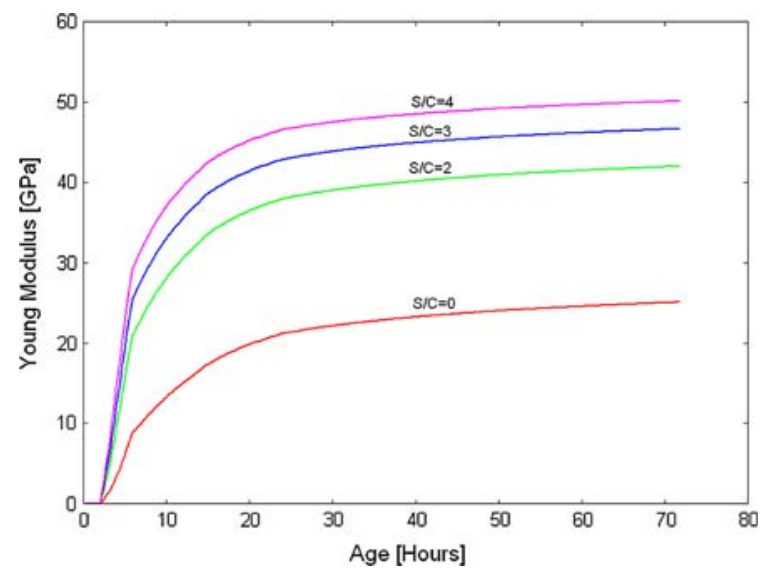

Fig. 12 Influence of the sand content $S / C$ on the homogenized Young's modulus 


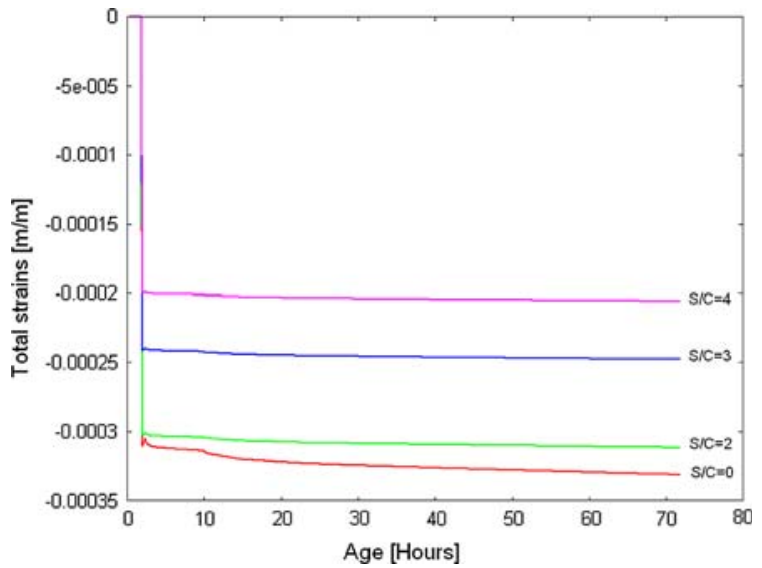

Fig. 13 Influence of the sand content $S / C$ on the autogenous shrinkage

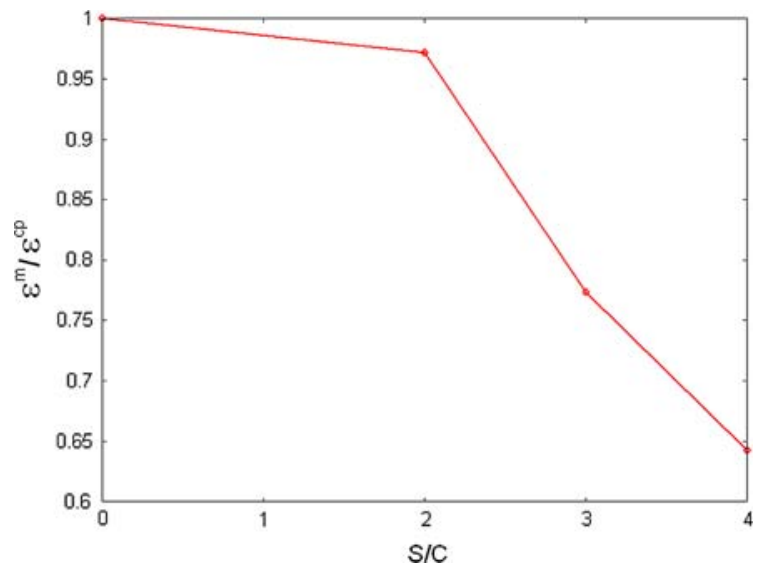

Fig. 14 Ratio between the autogenous shrinkage of mortar and the cement paste at $72 \mathrm{~h}\left(\varepsilon^{m} / \varepsilon^{c p}\right)$

shrinkage of mortars $\left(\varepsilon^{m}\right)$ on the autogenous shrinkage of the cement paste $\left(\varepsilon^{c p}\right)$ is plotted at $(72 \mathrm{~h})$. The increase of the Young's modulus as a function of the sand content is explained by the higher stiffness of the granular inclusions in comparison with the cement paste. The early-age deformations due to capillary pressure effects are therefore lower when the sand content increases.

\section{Conclusion}

In this work, we propose a multiscale approach for the calculation of the early-age autogenous shrinkage of cementitious materials. To model these phenomena, we have calculated the microstructure properties of cement pastes along the hydration time. The cement paste components have been taken into account in the calculation by using the chemical relations of the cement hydration [14]. Before the setting of the cement paste, a chemical shrinkage occurs and have been relied to the chemical shrinkage of each cement components [40]. After the setting of the cement paste, the material can be modeled by a porous medium formed by a solid phase and a capillary porosity. By solving a hydro-mechanical cellular problem in a REV, taking into account the pore pressure, and by applying the self-consistent scheme, we have calculated the homogenized mechanical properties and the macroscopic strain, or the autogenous shrinkage, of cement pastes. By considering the presence of rigid inclusions, as aggregates, we have modeled the autogenous shrinkage of mortars. Results obtained by the multiscale model show that we can predict the evolution of the chemical and self-desiccation shrinkage and the elastic properties. During setting, we have observed a small difference between the experimental and numerical values for the Young's modulus of cement pastes. That can be explained by a viscous behaviour of the cement paste during the setting time which changes from a fluid behaviour to a solid state. In this first approach, we have not considered the viscous part of the behaviour. Calculations of the autogenous shrinkage are relatively close to the experimental measurements. The sensitivity study has made possible to highlight, on the one hand the influence of some parameters on the cementitious materials properties at early-age, and on the other hand the sensitivity of calculations with respect to these parameters. The model is based on a large choice of the material properties and thus makes possible to study many formulations of cementitious materials.

In perspective, we wish to develop a tool able to predict the behaviour of cementitious materials during their service-life from the setting to their exploitation in various environments. SEM observations have shown the presence of micro-cracks surrounding aggregates in mortars after $48 \mathrm{~h}$. All most of these micro-cracks appear in the ITZ. In order to study the self-desiccation shrinkage up to few days, a coupling with a damage model will be studied. 


\section{Appendix A: Chemical relations of the cement hydration [50]}

$$
\begin{aligned}
& \mathrm{C}_{3} \mathrm{~S}+5.3 \mathrm{H} \rightarrow \mathrm{CSH}+1.3 \mathrm{CH} \\
& \mathrm{C}_{2} \mathrm{~S}+4.3 \mathrm{H} \rightarrow \mathrm{CSH}+0.3 \mathrm{CH} \\
& \mathrm{C}_{3} \mathrm{~A}+6 \mathrm{H} \rightarrow \mathrm{C}_{3}(\mathrm{~A}, \mathrm{~F}) \mathrm{H}_{6} \\
& \mathrm{C}_{4} \mathrm{AF}+10 \mathrm{H} \rightarrow \mathrm{C}_{3}(\mathrm{~A}, \mathrm{~F}) \mathrm{H}_{6}+\mathrm{FH}_{3}+\mathrm{CH} \\
& \mathrm{C}_{3} \mathrm{~A}+3 \mathrm{C} \overline{\mathrm{S}} \mathrm{H}_{2}+26 \mathrm{H} \rightarrow \mathrm{C}_{6} \mathrm{AS}_{3} \mathrm{H}_{32} \\
& \mathrm{C}_{4} \mathrm{AF}+3 \mathrm{C} \overline{\mathrm{S}} \mathrm{H}_{2}+30 \mathrm{H} \rightarrow \mathrm{C}_{6} \mathrm{AS}_{3} \mathrm{H}_{32}+\mathrm{FH}_{3}+\mathrm{CH} \\
& 2 \mathrm{C}_{3} \mathrm{~A}+\mathrm{C}_{6} \mathrm{AS}_{3} \mathrm{H}_{32}+4 \mathrm{H} \rightarrow 3 \mathrm{C}_{4} \mathrm{AS}_{12} \\
& 2 \mathrm{C}_{4} \mathrm{AF}+\mathrm{C}_{6} \mathrm{~A}_{3} \mathrm{H}_{32}+12 \mathrm{H} \rightarrow 3 \mathrm{C}_{4} \mathrm{AS} \mathrm{SH}_{12}+2 \mathrm{FH}_{3} \\
& \quad+2 \mathrm{CH}
\end{aligned}
$$

\section{Appendix B: The Eshelby's problem [21]}

The strain concentration tensors $\underset{\sim}{A}\rangle_{I}$ and $\left.\underset{\sim}{\langle A}\right\rangle_{I I}$ check the following identity:

$\underset{\sim}{I}=f_{1}\langle\underset{\sim}{A}\rangle_{I}+f_{2}\langle\underset{\sim}{A}\rangle_{I I}$

where $I$ indicates the fourth-order identity tensor. Consequently, the equation (26) in (13) allows to write:

$\underset{\sim}{C^{h o m}}=\underset{\sim}{C^{1}}+\left(1-f_{1}\right)\left(\underset{\sim}{C^{2}}-\underset{\sim}{C^{1}}\right):\langle\underset{\sim}{A}\rangle_{I I}$

where $\langle A\rangle_{I I}$ is defined by the following relation:

$\langle\underset{\sim}{A}\rangle_{I I}=\left[\underset{\sim}{I}+P_{\sim}^{1}:\left({\underset{\sim}{C}}^{2}-\underset{\sim}{C^{h o m}}\right)\right]^{-1}$

where $P^{1}$ represents the Eshelby tensor and for spherical inclusions we write:

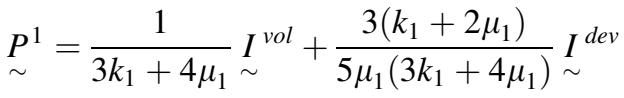

with ${\underset{\sim}{I}}^{v o l}=\frac{1}{3} \delta_{i j} \delta_{k l}$ and $I_{\sim}^{v o l}+{\underset{\sim}{I}}^{d e v}=\underset{\sim}{I}$ where $\underline{\underline{\delta}}$ is the second-order identity tensor.

\section{References}

1. Aboudi J (1991) Mechanics of composite materials: a unified micromechanical approach. Elsevier Science Publishers B.V., Amsterdam

2. Acker P (1992) Retraits et fissurations du béton. Documents scientifiques et techniques, Association Française Pour la Construction (AFPC)

3. Acker P, Ulm FJ (2001) Creep and shrinkage of concrete: physical origins and practical measurements. Nucl Eng Des 203:143-158
4. Antczak E, Defer D, Elaoami M, Chauchois A, Duthoit B (2007) Monitoring and thermal characterisation of cement matrix materials using non-destructive testing. NDT E Int 40(6):428-438

5. Avrami M (1939) Kinetics of phase change. I. general theory. J Chem Phys 7:1103

6. Avrami M (1940) Kinetics of phase change. II. transformation-time relations for random distribution of nuclei. $\mathrm{J}$ Chem Phys 8:212

7. Ballim Y, Graham P (2004) Early-age heat evolution of clinker cements in relation to microstructure and composition: implications for temperature development in large concrete elements. Cem Concr Compos 26(5):417-426

8. Baroghel-Bouny V, Kheirbek A (2001) Effect of mixparameters on autogenous deformations of cement pastesmicrostructural interpretations. Concr Sci Eng 3(9): 23-38

9. Baroghel-Bouny V, Mainguy M, Lassabatere T, Coussy O (1999) Characterization and identification of equilibrium and transfer moisture properties for ordinary and highperformance cementitious materials. Cem Concr Res 29:1225-1238

10. Bentz D, Garboczi E (1991) Percolation phases in a threedimensional cement paste microstructure model. Cem Concr Res 21:325-344

11. Bentz D, Garboczi E, Martys N (1996) Application of digital-image-based models to microstructure, transport properties, and degradation of cement-based materials. In: Jennings $\mathrm{H}$ (eds) Modelling of microstructure and its potential for studying transport properties and durability. Kluwer Academic Publisher, pp 167-185

12. Bentz D, Garboczi E, Haecker C, Jensen O (1999) Effects of cement particle size distribution on performance properties of portland cement-based materials. Cem Concr Res 29:1663-1671

13. Berliner R, Popovici M, Herwig K, Berliner M, Jennings H, Thomas J (1998) Quasielastic neutron scattering study of the effect of water-to-cement ratio on the hydration kinetics of tricalcium silicate. Cem Concr Res 28(2):231-243

14. Bernard O, Ulm F, Lemarchand E (2003) A multiscale micromechanics-hydration model for the early-age elastic properties of cement-based materials. Cem Concr Res 33:1293-1309

15. Bjøntegaard $\varnothing$ (1999) Thermal dilation and autogenous deformation as driving forces to self-induced stresses in high performance concrete. $\mathrm{PhD}$ thesis, NTNU Division of Structural Engineering, Trodheim

16. Bornert M, Bretheau T, Gilormini P (2001) Homogénéisation en mécanique des matériaux, vol Tome 1. Hermès Sciences Publications, Paris

17. Bouasker M (2007) Experimental and numerical studies of the autogenous deformations of very early-age cement pastes with or without granular inclusions. $\mathrm{PhD}$ thesis, University of Nantes, France (in French)

18. Bouasker M, Mounanga P, Khelidj A, Coué R (2008) Free autogenous strain of early-age cement paste: metrological development and critical analysis. Adv Cem Res 20(2): $75-84$

19. De Schutter G, Taerwe L (1995) Specific heat and thermal diffusivity of hardening concrete. Mag Concr Res 47(172): 203-208 
20. Dormieux L, Molinari A, Kondo D (2002) Micromechanical approach to the behavior of poroelastic materials. J Mech Phys Solids 50:2203-2231

21. Eshelby J (1957) The determination of the elastic field of an ellipsoidal inclusion and related problems. Proc R Soc Lond A241:376-396

22. Fuji K, Kondo W (1974) Kinetics of the hydration of tricalcium silicate. J Am Ceram Soc 57:492-502

23. Garcia Boivin S (1999) Retrait au jeune âge du béton : Développement d'une méthode expérimentale et contribution à l'analyse physique du retrait endogène. $\mathrm{PhD}$ thesis, Ecole Nationale des Ponts et Chaussées, Marne-laVallée

24. Grondin F, Dumontet H, Ben Hamida A, Mounajed G, Boussa H (2007) Multi-scales modelling for the behaviour of damaged concrete. Cem Concr Res 37:1453-1462

25. Guidoum A, Navi P, Huet C (1995) 3d numerical analysis of long term behaviour on concrete-like composite material. In: Proceedings of research and development in the field of dams, CIGB-ICOLD, Crans-Montana, pp 289-298

26. Haecker CJ, Garboczi E, Bullard J, Bohn R, Sun Z, Shah S, Voigt T (2005) Modeling the linear elastic properties of portland cement paste. Cem Concr Res 35(10):1948-1960

27. Hill R (1965) A self-consistent mechanics of composite materials. J Mech Phys Solids 13:213-222

28. Jennings $\mathrm{H}$ (2000) A model for the microstructure of calcium silicate hydrate in cement paste. Cem Concr Res 30(1):101-116

29. Kada H, Lachemi M, Petrov N, Bonneau O, Atcin PC (2002) Determination of the coefficient of thermal expansion of high performance concrete from initial setting. Mater Struct 35(245):35-41

30. Kishi T, Maekawa K (1995) Multi-component model for hydration heating of portland cement. In: Proceedings of JSCE, no. 526/V-29, pp 97-109 (in Japanese)

31. Kovler K, Zhutovsky S (2006) Overview and future trends of shrinkage research. Mater Struct 39(9):827-847

32. Le Chatelier H (1900) Sur les changements de volume qui accompagnent le durcissement des ciments. Technical report 5, Bulletin de la Société pour l'Encouragement Industriel National

33. Lee HK, Lee KM, Kimy B (2003) Autogenous shrinkage of high-performance concrete containing fly ash. Mag Concr Res 55(6):507-515

34. Lemarchand E (2001) Contribution de la micromécanique à l'étude des phénomènes de transport et de couplage poromécanique des les milieux poreux : application aux phénomènes de gonflement dans les géomatériaux. $\mathrm{PhD}$ thesis, Ecole Nationale des Ponts et Chaussées

35. Loukili A, Chopin D, Khelidj A, Le Touzo JY (2000) A new approach to determine autogenous shrinkage of mortar at an early age considering temperature history. Cem Concr Res 30(6):915-922

36. Mehta P, Monteiro P (1993) Concrete: structure, properties, and methods, 2nd edn. Prentice-Hall, Englewood Cliffs

37. Mindess S (1989) Interface in concrete. Materials Science of Concrete, American Ceramic Society, Westerville

38. Mounajed G, Grondin F, Dumontet H, Ben Hamida A (2006) Digital concrete: a multi-scale approach for the concrete behavior. J Comput Methods Sci Eng 6(5-6):325-337
39. Mounanga P, Khelidj A, Bastian G (2004) Experimental study and modelling approaches for the thermal conductivity evolution of hydrating cement paste. Adv Cem Res 16(3):95-103

40. Mounanga P, Khelidj A, Loukili A, Baroghel-Bouny V (2004) Predicting $\mathrm{Ca}(\mathrm{OH})_{2}$ content and chemical shrinkage of hydrating cement pastes using analytical approach. Cem Concr Res 34(2):255-265

41. Navi P, Pignat C (1996) Simulation of cement hydration and the connectivity of the capillary pore space. Adv Cem Based Mater 4:58-67

42. Obeid W, Mounajed G, Alliche A (2001) Mathematical formulation of thermo-hygro-mechanical coupling problem in non-saturated porous media. Comput Methods Appl Mech Eng 190:5105-5122

43. Obeid W, Mounajed G, Alliche A (2002) Experimental identification of biot's hydro-mechanical coupling coefficient for cement mortar. Mater Struct 35:229-236

44. Odler I (2001) Hydration, setting and hardening of Portland cement. In: Lea's chemistry of cement and concrete, 4th edn, Butterworth-Heinemann, Oxford, pp 241-289

45. Pichler C, Lackner R, Mang H (2007) A multiscale micromechanics model for the autogenous-shrinkage deformation of early-age cement-based materials. Eng Fract Mech 74:34-58

46. Powers TC, Brownyard TL (1948) Studies of the physical properties of hardened portland cement paste. Bulletin 22, part 9, Research Laboratories of the Portland Cement Association

47. Sarkis M, Granju JL, Arnaud M, Escadeillas G (2002) Coefficient de dilatation thermique d'un mortier frais. Mater Struct 35(251):415-420

48. Smaoui S, Ben Hamida A, Djeran-Maigre I, Dumontet $\mathrm{H}$ (2006) Micro-macro approaches coupled to an iterative process for nonlinear porous media. Comput Mater Contin 4(3): $153-162$

49. Springenschmidt R (ed) (1994) Proceedings of the RILEM international symposium on thermal cracking in concrete at early ages, E\&FN Spon, London

50. Taylor H (1990) Cement chemistry. Academic Press, New York

51. Tazawa E, Miyazawa S (1995) Influence of cement and admixture on autogenous shrinkage of cement paste. Cem Concr Res 25(2):281-287

52. Tazawa E, Miyazawa S, Kasai T (1995) Chemical shrinkage and autogenous shrinkage of hydrating cement paste. Cem Concr Res 25(2):288-292

53. Tennis P, Jennings $H$ (2000) A model for two types of calcium silicate hydrate in the microstructure of portland cement paste. Cem Concr Res 30(6):855-863

54. Torrenti J, Benboudjema F (2005) Mechanical threshold of cementitious materials at early age. Mater Struct 38(3): 299-304

55. Torrenti J, Aristaghes P, Dombernovski K, Edon F, Guenot I, Monachon P (1995) La simulation des effets thermiques dans le béton au jeune âge : Exemples d'applications. In: Annales de l'ITBTP, Série Béton 322, vol 535, série Béton 322, 3-27, ITBTP, pp 3-27

56. Turcry P, Loukili A, Barcelo L, Casabonne JM (2002) Can the maturity concept be used to separate the autogenous 
shrinkage thermal deformation of cement paste at early age? Cem Concr Res 32(9):1443-1450

57. Van Breugel K (1991) Simulation of hydration and formation of structure in hardening cement-based materials. $\mathrm{PhD}$ thesis, TU Delft, Delft
58. Weiss J (2002) Experimental determination of the "TimeZero", early-age cracking in cementitious systems. RILEM, state of the art report tc eas 6.1

59. Young J, Hansen W (1987) Microstructural development during hydration of cement. Mater Res Soc 85:313-322 